\title{
Sensitive Detection of Baicalein Based on GR/DNA/GCE
}

Ningning Zhang ${ }^{1}, \mathrm{Xu} \mathrm{Zhu}^{2, *}$, Baoxia Liu $^{2}$, Zhu Chang ${ }^{2}$, Yuanqiang Hao ${ }^{2}$, Yintang Zhang ${ }^{2}$,Maotian Xu ${ }^{2}$, Baoxian $\mathrm{Ye}^{1}$

${ }^{1}$ College of Chemistry and Molecular Engineering, Zhengzhou University, Zhengzhou 450001, People's Republic of China

${ }^{2}$ Henan Key Laboratory of Biomolecular Recognition and Sensing, College of Chemistry and Chemical Engineering, Henan Joint International Research Laboratory of Chemo/Biosensing and Early Diagnosis of Major Diseases, Shangqiu Normal University, Shangqiu 476000, People's Republic of China

*E-mail: ocina@yeah.net

doi: $10.20964 / 2018.05 .56$

Received: 15 December 2017 / Accepted: 4 March 2018 / Published: 10 April 2018

We report herein a sensitive electrochemical assay for the detection of baicalein. The highly-active working electrode was obtained by decorating the glassy carbon electrode modified with graphene and DNA (GR/DNA/GCE), which was characterized by cyclic voltammetry (CV) and electrochemical impedance spectroscopy (EIS). Electrochemical behavior of baicalein on the (GR/DNA/GCE) was systematically studies. Under optimized conditions, the typical oxidation current was found linear with concentration of baicalein in a range of $7.3 \times 10^{-7} \sim 1.17 \times 10^{-4} \mathrm{M}$ with a low detection of $3.2 \times 10^{-7}$ M.

Keywords: Baicalein, Electrochemical sensor, Graphene, DNA

\section{FULL TEXT}

(C) 2018 The Authors. Published by ESG (www.electrochemsci.org). This article is an open access article distributed under the terms and conditions of the Creative Commons Attribution license (http://creativecommons.org/licenses/by/4.0/). 